\title{
META-ANALYSIS: TYPES OF MEDIA AND CHARACTERISTICS OF PHYSICAL MATERIALS SUITABLE FOR PHYSICS LEARNING MEDIA BASED ON ADOBE FLASH SOFTWARE
}

\author{
Hasbi Azis ${ }^{* 1}$, Mutia Risma $^{2)}$, Sinta Yolanda ${ }^{3)}$, Usmeldi $^{4)}$, Desnita $^{5)}$ \\ ${ }^{1,2,3)}$ Physics graduate student, FMIPA Universitas Negeri Padang \\ ${ }^{4,5)}$ Lecturer of Physics Education Master Program, FMIPA Universitas Negeri Padang \\ e-mail: * hasbiazis14@gmail.com \\ mutiarisma10@gmail.com \\ sintayolanda11@gmail.com \\ usmeldy@yahoo.co.id \\ desywaznadil@gmail.com
}

\begin{abstract}
This research aimed to analyze the types of media and the characteristics of physics materials that are suitable for use in the development of physics learning media, using Adobe Flash software. The research uses a meta-analysis method, which is a method for analyzing many of the research that has been done. This research uses secondary data obtained from previous research in the form of journals related to the media using Adobe Flash software for senior high school physics subjects. The journals examined in this research consisted of 20 research articles that developed an adobe flash-based interactive learning media for physics learning in senior high schools. The number of articles reviewed consisted of 3 articles from international journals and 17 articles from national journals. Based on the results of the analysis that has been done, found 13 physics materials obtained from 20 journals analyzed, where the concepts of temperature, heat, and transfer are the most widely used material as content in the development of physics learning media based on Adobe Flash software. While the type of media that is widely used in computer-based learning media.
\end{abstract}

Keywords: meta-analysis, physics, learning media, adobe flash. 


\title{
META-ANALISIS: JENIS MEDIA DAN KARAKTERISTIK MATERI FISIKA YANG COCOK DIGUNAKAN DALAM PENGEMBANGAN MEDIA PEMBELAJARAN FISIKA BERBASIS SOFTWARE ADOBE FLASH
}

\author{
Hasbi Azis $^{* 1)}$, Mutia Risma ${ }^{1)}$, Sinta Yolanda ${ }^{1)}$, Usmeldi $^{2)}$, Desnita $^{2)}$ \\ ${ }^{1,2,3)}$ Mahasiswa pascasarjana pendidikan fisika FMIPA Universitas Negeri Padang \\ ${ }^{4,5)}$ Dosen Program Studi Magister Pendidikan Fisika, FMIPA Universitas Negeri Padang
}

\begin{abstract}
Abstrak
Penelitian ini bertujuan untuk menganalisis jenis-jenis media dan karakteristik materi fisika yang sesuai untuk digunakan dalam pengembangan media pembelajaran fisika, menggunakan perangkat lunak Adobe Flash. Penelitian ini menggunakan metode meta-analisis yang merupakan metode untuk menganalisis banyak penelitian-penelitian yang telah dilakukan. Penelitian ini menggunakan data sekunder yang diperoleh dari penelitian sebelumnya berupa jurnal yang terkait dengan media menggunakan perangkat lunak Adobe Flash untuk mata pelajaran fisika SMA. Jurnal yang diteliti dalam penelitian ini terdiri dari 20 artikel penelitian yang mengembangkan media pembelajaran interaktif berbasis Adobe Flash untuk pembelajaran fisika di sekolah menengah. Jumlah artikel yang dikaji terdiri dari 3 artikel berasal dari jurnal internasional dan 17 artikel dari jurnal nasional. Berdasarkan hasil analisis yang telah dilakukan, ditemukan13 materi fisika yang diperoleh dari 20 jurnal yang dianalisis, dimana konsep suhu, panas, dan transfer adalah materi yang paling banyak digunakan sebagai konten dalam pengembangan media pembelajaran fisika berbasis perangkat lunak Adobe Flash. Sedangkan jenis media yang banyak digunakan adalah media pembelajaran berbasis komputer.
\end{abstract}

Kata kunci: meta-analisis, fisika, media pembelajaran, adobe flash.

\section{Pendahuluan}

Abad 21 merupakan abad yang sarat dengan perkembangan teknologi informasi dan komunikasi. Bersamaan dengan hal tersebut, ilmu pengetahuan juga ikut berkembang mengikuti derasnya perubahan yang terjadi, salah satunya melalui penyempurnaan kurikulum pendidikan. Kurikulum Tingkat Satuan Pendidikan (KTSP) disempurnakan menjadi kurikulum 2013 (K13) dengan harapan dapat memperbaiki sistem pendidikan di Indonesia dan meningkatkan kualitas sumber daya manusia melalui pendidikan.

Salah satu mata pelajaran yang harus dikuasai peserta didik sesuai dengan K13 adalah mata pelajaran fisika. Mengingat fisika merupakan ilmu pengetahuan yang mencakup pengetahuan terhadap sifat fisis dari suatu objek maupun kejadian, seperti halnya bentuk, berat, sera bagaimana objek-objek tersebut saling berinteraksi, sehingga dalam penyampaiannya harus didukung dengan media yang sesuai dan memadai agar dapat mencapai tujuan pembelajaran yang telah ditetapkan (Zaman, et al. 2012)

Media merupakan perantara atau medium untuk menyampaikan pesan (Sadaiman, 2014). Dengan demikian, media pembelajaran dapat diartikan sebagai alat bantu untuk menyampaikan materi pembelajaran kepada peserta didik. Menurut Usmeldi (2017), media pembelajaran adalah alat yang digunakan dalam rangka lebih mengefektifkan komunikasi dan interaksi antara guru dengan siswa dalam proses pembelajaran di sekolah. Penggunaan media dalam proses pembelajaran, khususnya pembelajaran fisika diharapkan dapat membantu peserta didik untuk lebih mudah memahami materi sehingga tercipta pembelajaran yang efektif dan efisien.

Selain media pembelajaran, pendidik juga merupakan komponen penting dalam proses pembelajaran. Pendidik diwajibkan untuk mampu memilih, menggunakan dan mengembangkan media pembelajaran dalam rangka meningkatkan efisiensi dan efektivitas proses pembelajaran. Dengan mengembangkan media pembelajaran yang menarik, memanfaatkan software dan bersifat interaktif, 
diharapkan dapat meningkatkan motivasi dan semangat peserta didik untuk belajar. Hal ini sesuai dengan pernyataan Kurniawati et al. (2016) yang menyatakan bahwa pembuatan media pembelajaran dengan aplikasi software diharapkan dapat meningkatkan minat dan motivasi belajar siswa, lebih jauh dapat meningkatkan hasil belajar yang dicapai.

Namun, kenyataan yang terjadi belum sepenuhnya sesuai dengan harapan yang telah dipaparkan. Pembelajaran fisika masih didominasi oleh pembelajaran yang bersifat konvensional dan berpusat kepada pendidik. Hal ini membuat pembelajaran menjadi kurang menarik bagi peserta didik karena belum memberikan kesempatan bagi peserta didik untuk mengembangkan pengetahuannya (Rohmani et al, 2015). Selain itu, penggunaan media pembelajaran masih kurang maksimal sehingga menimbulkan jenuh pada diri peserta didik, karena hanya mendengarkan ceramah dari pendidik. Banyak faktor yang menyebabkan hal ini terjadi, salah satunya adalah tidak tersedianya media pembelajaran fisika di suatu sekolah dan kurangnya kemampuan guru dalam mengembangkan media pembelajaran fisika yang menarik dan interaktif. Software Adobe Flash merupakan salah satu software yang dapat membuat media pembelajaran digital dan interaktif. Hal tersebut telah dibuktikan dengan beberapa penelitian terkait software tersebut. Salah satunya adalah Rohmani et al. (2015) yang mendapatkan bahwa penerapan media pembelajaran fisika menggunakan Adobe Flash untuk membuat multimedia interaktif yang dapat meningkatkan hasil belajar peserta didik.

Berdasarkan permasalahan yang telah dijelaskan, telah banyak dilakukan penelitian untuk mengembangkan media pembelajaran fisika menggunakan software tertentu. Salah satu software yang digunakan adalah Adobe Flash. Mengingat banyaknya penelitian pengembangan media menggunakan software Adobe Flash, maka perlu dilakukan penelitian meta-analisis pengembangan media pembelajaran interaktif berbasis software Adobe Flash pada pembelajaran fisika. Penelitian meta-analisis ini bertujuan untuk menganalisis jenis media dan karakter materi fisika yang cocok digunakan dalam pengembangan media pembelajaran fisika menggunakan software Adobe Flash.

\section{Bahan dan Metode}

Penelitan ini menggunakan metode penelitian meta-analisis dengan merangkum beberapa jurnal penelitian terkait media pembelajaran interaktif berbasis software Adobe Flash. Penelitian meta-analisis ini bersifat kuantitatif, dikarenakan menggunakan angka-angka dan statistik dalam pengolahannya dengan menyusun serta merangkum informasi dari beberapa penelitian yang telah dilakukan (Glass et al., 1981).

Penelitian meta-analisis ini menganalisis jurnal sebanyak 20 jurnal terkait media pembelajaran dengan menggunakan software Adobe Flash dari tahun 2016-2019 dengan pemberian kode. Pengkodean pada metaanalisis merupakan langkah penting agar dapat mempermudah pengumpulan data untuk dianalisis. Dikarenakan hal tersebut, pada meta-analisis ini dilakukan dengan lembar pemberian kode (coding category). Variabelvariabel yang digunakan dalam pemberian kode dimaksudkan agar lebih mudah menghasilkan informasi yang diperlukan dalam penelitian ini. Tahap-tahap tabulasi data adalah sebagai berikut;

1. Mengidentifikasi variabel-variabel penelitian yang telah ditemukan dan dimasukan ke dalam kolom variabel yang sesuai.

2. Mengidentifikasi frekuensi jurnal berdasarkan indikator yang akan diteliti.

3. Menghitung frekuensi relatif.

4. Mengidentifikasi rata-rata kevalidan materi untuk setiap subjek penelitian.

5. Mengidentifikasi rata-rata kevalidan media untuk setiap subjek penelitian;

Perhitungan rata-rata akhir tingkat validitas materi dan validitas media menggunakan persamaan (1).

$$
\text { Rata }- \text { Rata }=\frac{X}{Y}
$$

Ket: $\mathrm{x}=$ jumlah persentase yang diperoleh.

$\mathrm{y}=$ banyak data.

Dengan kriteria penilaian seperti Tabel 1 sebagai berikut: 
Tabel 1. Kategori suatu produk dikatakan valid

\begin{tabular}{cc}
\hline Interval & Kategori \\
\hline $81-100$ & Sangat Valid \\
$61-80$ & Valid \\
$41-60$ & Cukup Valid \\
$21-40$ & Kurang Valid \\
$0-20$ & Tidak valid \\
\hline
\end{tabular}

Sumber : (Riduwan, 2010)

\section{Hasil dan Pembahasan}

Distribusi sampel penelitian dapat dilihat pada Tabel 2 di bagian hasil dan pembahasan. Berdasarkan Tabel 2 diperlihatkan jenis media, materi, validasi materi dan validasi media tiaptiap jurnal, didapati dari 20 jurnal terdapat 3 jurnal yang tidak melampirkan nilai validasi media dan materi. Melalui 20 jurnal tersebut dilakukan analisis lanjutan terkait tujuan dari penelitian meta-analisis ini.

Tabel 2. Distribusi tiap jurnal

\begin{tabular}{|c|c|c|c|c|c|c|}
\hline No & Judul & Tahun & Jenis Media & Materi & $\begin{array}{c}\text { Validitas } \\
\text { Materi } \\
(\%)\end{array}$ & $\begin{array}{c}\text { Validitas } \\
\text { Media } \\
(\%)\end{array}$ \\
\hline 1 & $\begin{array}{l}\text { Pengembangan Media } \\
\text { Pembelajaran Interaktif } \\
\text { untuk Sekolah Menengah } \\
\text { Atas Kelas XI Pada Pokok } \\
\text { Bahasan Momentum }\end{array}$ & 2017 & $\begin{array}{l}\text { Media } \\
\text { Pembelajaran }\end{array}$ & $\begin{array}{l}\text { Momentum } \\
\& \text { Impuls }\end{array}$ & 76.39 & 68.75 \\
\hline 2 & $\begin{array}{l}\text { Pengembangan Media } \\
\text { Pembelajaran Dengan } \\
\text { Menggunakan Adobe Flash } \\
\text { CS6 Pada Materi Hukum } \\
\text { Newton Tentang Gerak } \\
\text { danPenerapannya }\end{array}$ & 2016 & $\begin{array}{l}\text { Media } \\
\text { Pembelajaran }\end{array}$ & $\begin{array}{l}\text { Hukum } \\
\text { Newton } \\
\text { Tentang } \\
\text { Gerak }\end{array}$ & 100 & 100 \\
\hline 3 & $\begin{array}{l}\text { Pengembangan Media } \\
\text { Pembelajaran Fisika } \\
\text { Berbasis Multimedia } \\
\text { Interaktif Terintegrasi } \\
\text { Dengan LKS Pokok } \\
\text { Bahasan Hukum Newton } \\
\text { Tentang Gerak Kelas X } \\
\text { SMA/MA (Rohmani et } \\
\text { al., 2015) }\end{array}$ & 2015 & Multimedia & $\begin{array}{l}\text { Hukum } \\
\text { Newton } \\
\text { Tentang } \\
\text { Gerak }\end{array}$ & 80.20 & 76.80 \\
\hline 4 & $\begin{array}{l}\text { Pengembangan Multimedia } \\
\text { Interaktif Berbasis Android } \\
\text { Pada Mata Pelajaran Fisika } \\
\text { Pokok Bahasan Suhu, Kalor, } \\
\text { dan Perpindahan Kalor } \\
\text { Untuk SMA Kelas XI }\end{array}$ & 2016 & $\begin{array}{l}\text { Multimedia } \\
\text { Berbasis } \\
\text { Android }\end{array}$ & $\begin{array}{l}\text { Suhu, } \\
\text { Kalor dan } \\
\text { Perpindaha } \\
\text { nnya }\end{array}$ & 97.02 & 86.93 \\
\hline 5 & $\begin{array}{l}\text { Pengembangan Media } \\
\text { Pembelajaran Fisika SMA } \\
\text { Kelas XI Menggunakan } \\
\text { Adobe Flash Proffesional } \\
\text { CS6 Pada Materi } \\
\text { Momentum dan Impuls }\end{array}$ & 2019 & Multimedia & $\begin{array}{l}\text { Momentum } \\
\text { dan Impuls }\end{array}$ & 76.56 & 77.50 \\
\hline
\end{tabular}




\begin{tabular}{|c|c|c|c|c|c|c|}
\hline No & Judul & Tahun & Jenis Media & Materi & $\begin{array}{c}\text { Validitas } \\
\text { Materi } \\
(\%)\end{array}$ & $\begin{array}{c}\text { Validitas } \\
\text { Media } \\
\text { (\%) }\end{array}$ \\
\hline 6 & $\begin{array}{l}\text { Pengembangan Media } \\
\text { Pembelajaran Fisika } \\
\text { Berbasis Adobe Flash CS6 } \\
\text { Pada Materi Pokok Fluida } \\
\text { Statis Untuk Siswa Kelas XI } \\
\text { SMA/MA }\end{array}$ & 2019 & $\begin{array}{l}\text { Media } \\
\text { Pembelajaran }\end{array}$ & $\begin{array}{l}\text { Fluida } \\
\text { Statis }\end{array}$ & 87.50 & 87.00 \\
\hline 7 & $\begin{array}{l}\text { Pengembangan Media } \\
\text { Pembelajaran Berbasis 3D } \\
\text { PageFlip Fisika untuk } \\
\text { Materi Getaran dan } \\
\text { Gelombang Bunyi }\end{array}$ & 2016 & $\begin{array}{l}\text { Media } \\
\text { Berbasis } \\
\text { Android }\end{array}$ & $\begin{array}{l}\text { Getaran } \\
\text { dan } \\
\text { Gelombang }\end{array}$ & - & - \\
\hline 8 & $\begin{array}{l}\text { Pengembangan Media } \\
\text { Pembelajaran Fisika } \\
\text { Berbasis Adobe Flash Untuk } \\
\text { Menjelaskan Fisika Inti dan } \\
\text { Radioaktivitas Untuk SMA } \\
\text { Kelas XII }\end{array}$ & 2012 & Multimedia & $\begin{array}{l}\text { Fisika Inti } \\
\text { dan } \\
\text { Radioaktivi } \\
\text { tas }\end{array}$ & 81.50 & 80.07 \\
\hline 9 & $\begin{array}{l}\text { Media Pembelajaran Fisika } \\
\text { Modern Berbasis Android } \\
\text { Menggunakan Adobe Flash } \\
\text { CS6 Dengan Animasi Tiga } \\
\text { Dimensi Pada Materi Model } \\
\text { Atom Untuk Siswa Kelas } \\
\text { XII SMA }\end{array}$ & 2017 & $\begin{array}{l}\text { Media } \\
\text { Pembelajaran }\end{array}$ & $\begin{array}{l}\text { Model } \\
\text { Atom }\end{array}$ & 93.00 & 95.00 \\
\hline 10 & $\begin{array}{l}\text { Aplikasi Mobile Learning } \\
\text { Fisika Dengan } \\
\text { Menggunakan Adobe Flash } \\
\text { Sebagai Media } \\
\text { Pembelajaran Pendukung }\end{array}$ & 2012 & $\begin{array}{l}\text { Media } \\
\text { Berbasis } \\
\text { Android }\end{array}$ & $\begin{array}{l}\text { Suhu, } \\
\text { Kalor dan } \\
\text { Perpindaha } \\
\text { nnya }\end{array}$ & 82.00 & 83.00 \\
\hline 11 & $\begin{array}{l}\text { PF-60: Pengembangan } \\
\text { Media Pembelajaran Fisika } \\
\text { Dengan Program Adobe } \\
\text { Flash CS6 Berbasis } \\
\text { Keterampilan Proses Sains }\end{array}$ & 2012 & $\begin{array}{l}\text { Media } \\
\text { Pembelajaran }\end{array}$ & $\begin{array}{l}\text { Medan } \\
\text { Magnet }\end{array}$ & - & - \\
\hline 12 & $\begin{array}{l}\text { Development of Sound } \\
\text { Wave and Light Wave E- } \\
\text { Book Physics Based on } \\
\text { Scientific Approach to } \\
\text { Improve Sciece Process } \\
\text { Skills For Secondary School } \\
\text { Students }\end{array}$ & 2019 & $\begin{array}{l}\text { Media } \\
\text { Pembelajaran }\end{array}$ & $\begin{array}{l}\text { Gelombang } \\
\text { dan Cahaya }\end{array}$ & 99.00 & 82.00 \\
\hline 13 & $\begin{array}{l}\text { The Development of } \\
\text { Interactive Multimedia on } \\
\text { Science Learning Based } \\
\text { Adobe Flash CS6 }\end{array}$ & 2019 & Multimedia & $\begin{array}{l}\text { Konsep } \\
\text { Tekanan }\end{array}$ & 79.68 & 81.67 \\
\hline 14 & $\begin{array}{l}\text { Physics Education } \\
\text { (PhyEdu): Mechanical Wave } \\
\text { Media For Physics Learning }\end{array}$ & 2019 & $\begin{array}{l}\text { Media } \\
\text { Berbasis } \\
\text { Android }\end{array}$ & $\begin{array}{r}\text { Gelombang } \\
\text { dan Cahaya }\end{array}$ & 80.00 & 89.00 \\
\hline 15 & $\begin{array}{l}\text { Perancangan Pembuatan } \\
\text { Multimedia Pembelajaran }\end{array}$ & 2015 & Multimedia & Hukum & - & - \\
\hline
\end{tabular}




\begin{tabular}{|c|c|c|c|c|c|c|}
\hline No & Judul & Tahun & Jenis Media & Materi & $\begin{array}{c}\text { Validitas } \\
\text { Materi } \\
(\%)\end{array}$ & $\begin{array}{c}\text { Validitas } \\
\text { Media } \\
(\%)\end{array}$ \\
\hline & $\begin{array}{l}\text { "Hukum Newton Tentang } \\
\text { Gaya dan Gerak" Berbasis } \\
\text { Adobe Flash }\end{array}$ & & & $\begin{array}{l}\text { Newton } \\
\text { Tentang } \\
\text { Gerak }\end{array}$ & & \\
\hline 16 & $\begin{array}{l}\text { Aplikasi Mobile Learning } \\
\text { Fisika Dengan } \\
\text { Menggunakan Adobe Flash } \\
\text { Sebagai Media } \\
\text { Pembelajaran Pendukung }\end{array}$ & 2012 & $\begin{array}{l}\text { Media } \\
\text { Berbasis } \\
\text { Android }\end{array}$ & $\begin{array}{l}\text { Suhu, } \\
\text { Kalor dan } \\
\text { Perpindaha } \\
\text { nnya }\end{array}$ & 82.00 & 83.00 \\
\hline 17 & $\begin{array}{l}\text { Pengembangan Media } \\
\text { Pembelajaran Fisika } \\
\text { Berbasis Mobile Learning } \\
\text { dengan Menggunakan } \\
\text { Adobe Flash cs6 Siswa } \\
\text { Kelas XI MAN } 2 \text { Padang }\end{array}$ & 2017 & $\begin{array}{l}\text { Media } \\
\text { Berbasis } \\
\text { Android }\end{array}$ & Elastisitas & 91.96 & 92.96 \\
\hline 18 & $\begin{array}{l}\text { Pengembangan Media } \\
\text { Pembelajaran Fisika } \\
\text { Induktansi Menggunakan } \\
\text { Adobe Flash CS4 }\end{array}$ & 2015 & $\begin{array}{l}\text { Media } \\
\text { Pembelajaran }\end{array}$ & Induktansi & 79.00 & 76.50 \\
\hline 19 & $\begin{array}{l}\text { Desain Media Pembelajaran } \\
\text { Dalam Bentuk Buku Saku } \\
\text { Yang Berbasis Mobile } \\
\text { Aplication Menggunakan } \\
\text { Player Air For Android } \\
\text { Pada Adobe Flash } \\
\text { Profesional CS } 5.5 \text { Untuk } \\
\text { Materi Fisika SMA }\end{array}$ & 2013 & $\begin{array}{l}\text { Media } \\
\text { Berbasis } \\
\text { Android }\end{array}$ & $\begin{array}{l}\text { Suhu, } \\
\text { Kalor dan } \\
\text { Perpindaha } \\
\text { nnya }\end{array}$ & 87.50 & 88.25 \\
\hline 20 & $\begin{array}{l}\text { Pengembangan Media } \\
\text { Pembelajaran Berbasis } \\
\text { Scratch Pada Pokok } \\
\text { Bahasan Alat Optik }\end{array}$ & 2019 & $\begin{array}{l}\text { Media } \\
\text { Pembelajaran }\end{array}$ & Alat Optik & 70.00 & 91.07 \\
\hline
\end{tabular}

Tabel 3. Jenis media

\begin{tabular}{|c|c|c|c|c|c|}
\hline No & Jenis Media & $F$ & $\begin{array}{l}f r \\
(\%)\end{array}$ & $\begin{array}{c}\text { Validasi Materi } \\
(\%) \\
\end{array}$ & $\begin{array}{c}\text { Validasi Media } \\
(\%) \\
\end{array}$ \\
\hline 1 & $\begin{array}{l}\text { Media Pembelajaran Berbasis } \\
\text { Komputer }\end{array}$ & 8 & 40 & 86.41 & 85,76 \\
\hline 2 & $\begin{array}{l}\text { Multimedia Berbasis } \\
\text { Komputer }\end{array}$ & 4 & 20 & 78.81 & 79.36 \\
\hline 3 & Multimedia Berbasis Android & 1 & 5 & 97.02 & 86.93 \\
\hline 4 & $\begin{array}{l}\text { Media Pembelajaran Berbasis } \\
\text { Android }\end{array}$ & 7 & 35 & 84.29 & 87,24 \\
\hline
\end{tabular}

Distribusi jenis penelitian pada sampel yang dlakukan pada meta-analisis ini terkait distribusi jenis media dan rata-rata validasi materi dan media dapat dilihat pada Tabel 3.

Setelah dilakukan penelitian meta-analisis terkait penggunaan software Adobe Flash dalam pembuatan media interaktif, diperoleh bahwa jenis media pembelajaran berbasis komputer lebih sering digunakan pada pembelajaran fisika menggunakan software Adobe Flash dengan frekuensi relatif $40 \%$ 
yang mempunyai rata-rata validitas materi dan media berada pada kategori baik.

Hasil penelitian yang telah dipaparkan diperoleh bahwa jenis media pembelajaran yang sering digunakan pada pembelajaran fisika dengan software Adobe Flash adalah media pembelajaran berbasis komputer. Perkembangan teknologi informasi dan komunikasi, khususnya komputer memberikan dampak yang sangat berarti disetiap bidang kehidupan, contohnya bidang pendidikan. Hampir semua pekerjaan dalam dunia pendidikan menggunakan komputer sebagai sarananya.

Banyak faktor yang menyebabkan media pembelajaran berbasis komputer lebih sering digunakan dalam pengembangan media pembelajaran fisika. Pertama, menurut Jonassen (1995), media pembelajaran berbasis komputer memungkinkan peserta didik untuk merangkum apa yang telah ia pelajari. Kedua, dePorter et al. (2000) menyatakan bahwa media pembelajaran berbasis komputer membantu pendidik untuk menyampaikan pembelajaran dengan baik secara multisensory, baik melalui audio, visual, maupun kinestetik. Ketiga, media pembelajaran berbasis komputer dapat melatih dan meningkatkan kemampuan berpikir tingkat tinggi. Seperti yang kita tahu, pendidikan abad 21 menuntut penguasaan peserta didik secara menyeluruh, salah satunya peningkatan keterampilan berfikir tingkat tinggi. Ini artinya, media pembelajaran berbasis komputer dapat mendukung penguasaan kompetensi abad 21.

Media pembelajaran berbasis komputer lebih memungkinkan pembelajaran berlangsung secara interaktif. Berkaitan dengan hal ini, Winarno et al. (2009) menyatakan bahwa hasil penelitian dari Computer Technology Research (CTR) menunjukkan bahwa penggunaan media pembelajaran berbasis multimedia interaktif dapat membantu peserta didik untuk meraih hasil belajar $80 \%$ dari apa yang dipelajarinya. Menurut Escalada \& Zollman (1997), media pembelajaran berbasis komputer tidak hanya berperan untuk mengembangkan pemahaman saja, namun juga dapat mengembangkan keterampilan investigasi ilmiah dan inquri peserta didik. Hal ini membuktikan bahwa media pembelajaran berbasis komputer baik digunakan dalam pengembangan media pembelajaran, khusus- nya media pembelajaran fisika menggunakan software Adobe Flash.

Analisis selanjutnya terkait jenis materi yang digunakan sebagai konten dalam media pembelajaran berbasis Adobe Flash, dapat dilihat pada Tabel 3 berikut.

Tabel 3. Distribusi materi fisika

\begin{tabular}{|c|c|c|c|}
\hline No & Materi & $f$ & $\begin{array}{c}F r \\
(\%)\end{array}$ \\
\hline 1 & Momentum \& Impuls & 2 & 10 \\
\hline 2 & $\begin{array}{l}\text { Hukum Newton Tentang } \\
\text { Gerak }\end{array}$ & 3 & 15 \\
\hline 3 & $\begin{array}{l}\text { Suhu, Kalor dan } \\
\text { Perpindahannya }\end{array}$ & 4 & 20 \\
\hline 4 & Fluida Statis & 1 & 5 \\
\hline 5 & Getaran dan Gelombang & 1 & 5 \\
\hline 6 & $\begin{array}{l}\text { Fisika Inti dan } \\
\text { Radioaktivitas }\end{array}$ & 1 & 5 \\
\hline 7 & Model Atom & 1 & 5 \\
\hline 8 & Medan Magnet & 1 & 5 \\
\hline 9 & Konsep Tekanan & 1 & 5 \\
\hline 10 & Gelombang dan Cahaya & 2 & 5 \\
\hline 11 & Elastisitas & 1 & 5 \\
\hline 12 & Induktansi & 1 & 5 \\
\hline 13 & Alat Optik & 1 & 5 \\
\hline
\end{tabular}

Tabel 3 menunjukan analisis data terkait materi yang diterapkan pada media pembelajaran fisika berbasis software Adobe Flash. Terdapat 13 materi dari jurnal yang dianalisis dimana meteri suhu, kalor dan perpindahannya menjadi materi fisika yang paling sering diterapkan ke dalam media pembelajaran berbasis software Adobe Flash, serta diikuti materi hukum Newton. Selanjutnya, berdasarkan hasil penelitian meta-analisis yang telah dilakukan, diperoleh bahwa terdapat 13 materi dari jurnal yang telah dianalisis. Hal ini sesuai dengan hasil penelitian Surata, et al. (2020) yang menyatakan bahwa jenis materi yang digunakan sebagai konten dalam penelitian media pembelajaran sangat bervariasi. Salah satu hal yang harus diperhatikan dalam pengembangan media pembelajaran adalah kesesuaian dengan jenis dan karakteristik materi. Hal ini sangat menentukan keberhasilan proses pembelajaran menggunakan media. Pada penelitian ini diperoleh, bahwa meteri 
suhu, kalor, dan perpindahannya menjadi materi fisika yang paling sering diterapkan ke dalam media pembelajaran berbasis software Adobe Flash. Materi suhu dan kalor merupakan materi yang mudah dikarenakan karakteristik materinya gampang untuk ditemukan dalam kehidupan nyata dan seharihari. Hal ini sesuai dengan pernyataan Surata et al. (2020) bahwa tidak semua jenis media efisien untuk semua jenis materi fisika, semua itu tergantung pada karakteristik materi. Dapat dipahami bahwa materi suhu, kalor, dan perpindahannya menjadi materi fisika yang paling efisien digunakan dalam pengembangan media pembelajaran fisika berbasis software Adobe Flash.

\section{Kesimpulan dan Saran}

Berdasarkan hasil analisis yang telah dilakukan, maka disimpulkan dua hal sebagai berikut. Pertama, ditinjau dari aspek materi yang digunakan, terdapat 13 materi fisika dari 20 jurnal yang dianalisis. Meteri suhu, kalor, dan perpindahannya menjadi materi yang paling banyak diterapkan sebagai konten dalam pengembangan media pembelajaran berbasis software Adobe Flash. Kedua, ditinjau dari aspek media yang digunakan, diperoleh bahwa jenis media pembelajaran berbasis komputer paling banyak digunakan pada pengembangan media pembelajaran fisika menggunakan software Adobe Flash.

\section{Daftar Pustaka}

Aji, S.D. (2019). Physics Education (PhyEdu): Mechanical wave media for physics learning. Journal of Physics: Conference Series " $4^{\text {th }}$ Annual Applied Science and Enginerring Conference".

Arfiansyah, L. P., et al. (2019). Pengembangan media pembelajaran berbasis scratch pada pokok bahasan Alat Optik. Unnes Physics Educational Journal, 8(1), 66-74.

Astea, M., et al. (2012). Aplikasi mobile learning fisika dengan menggunakan Adobe Flash sebagai media pembelajaran pendukung. Journal Pendidikan dan Kebudayaan, 18(2).
Bayasari, A., Sunaryo, \& Iswanto B.H. (2012). Pengembangan media pembelajaran fisika berbasis adobe flash untuk menjekaskan Fisika Inti dan Radioaktivitas untuk SMA Kelas XII. Seminar Nasional Fisika.

DePorter, Bobbi, \& Hernacki, M. (2000). Quantum learning, membiasakan belajar menyenangkan (Diterjemahkan oleh Alwiyah Abdurrahman). Bandung: Kaifa.

Eka, E.Y., Budiawati, S., \& Fitriana, D. (2013). Desain media pembelajaran dalam bentuk buku saku yang berbasis mobile aplication menggunakan player air for android pada Adobe Flash Profesional CS 5.5 untuk materi fisika SMA. Seminar nasional fisika dan pendidikan fisika "Pembelajaran sains berbasis kearifan lokal.

Escalada, L.T., \& Zollman, D.A. (1997). An investigation on the effects of using interactive digital video in a physics classroom on student learning and attitudes. Journal of Research in Science Teaching, 34(5).

Fajarianto, O., Triono, \& Cahyadi, F. (2015). Perancangan pembuatan multimedia pembelajaran "Hukum Newton tentang gaya dan gerak" berbasis Adobe Flash. Jurnal Sisfotek Global, 5(1).

Glass, G.V., McGaw, B., \& Smith, M.L. (1981). Meta-analysis in Social Research. Beverly Hills. Calif: Sage.

Husono, La., et al. (2019). Pengembangan media pembelajaran fisika berbasis Adobe Flash CS6 pada materi pokok fluida statis untuk siswa kelas XI SMA/MA. Jurnal Penelitian Pendidikan Fisika, 4(4).

Jalaluddin, M., et al. (2019). Pengembangan media pembelajaran fisika sma kelas XI menggunakan Adobe Flash Proffesional CS6 pada materi momentum dan impuls. Jurnal Penelitian Pendidikan Fisika, 4(4).

Jannah, R. (2017). Pengembangan media pembelajaran fisika berbasis mobile learning dengan menggunakan Adobe Flash cs6 siswa kelas XI MAN 2 Padang. Natural Science Journal, 3(2).

Jonassen, D.H. (1995). Thinking Technology: Toward a Constructivist Design Model. Journal of Education Technology, 34(4).

Kurniawati, H., Desnita, \& Siswoyo. (2016). Pengembangan media pembelajaran berbasis 3D PadeFlip fisika untuk materi 
getaran dan gelombang bunyi. Jurnal Penelitian \& Pengembangan Pendidikan Fisika, 2(1).

Prasetya, A. M., et al. (2018). Pengembangan multimedia interaktif berbasis android pada mata pelajaran fisika pokok bahasan suhu, kalor dan perpindahan kalor untuk SMA kelas XI. Jurnal Inovasi dan Pembelajaran Fisika.

Rahayu, Sy., et al. (2019). Development of sound wave and light wave e-book physics based on scientific approach to improve sciece process skills for secondary school students. AIP Conference Proceedings "The $8^{\text {th }}$ Nasional Physics Seminar 2019".

Rezeki, S. (2017). Pengembangan Media Pembelajaran Interaktif Untuk Sekolah Menengah Atas Kelas XI Pada Pokok Bahasan Momentum. Jurnal Penelitian \& Pengembangan Pendidikan Fisika, 3(1).

Riduwan. (2010). Skala Pengukuran Variabelvariabel Penelitian. Bandung: Alfabeta.

Rohmani. Widha Sunarno, \& Sukarmin. (2015). Pengembangan media pembelajaran fisika berbasis multimedia interaktif erintegrasi dengan LKS pokok bahasan hukum Newton tentang gerak kelas X SMA/MA. Jurnal Inkuiri, 4(1).

Sadaiman, A.S, et al. (2014). Media Pembelajaran. Jakarta: Rajawali Pers.

Setia, O.M. (2018). Pengembangan media pembelajaran dengan menggunakan Adobe Flash CS6 pada materi hukum
Newton tentang gerak dan penerapannya. Jurnal Edufisika, 3(1).

Sukariasih, L., et al. (2019). The development of interactive multimedia on science learning based Adobe Flash CS6. International Journal for Educational and Vocational Studies, 1(4).

Susilawati, et al. (2017). Media pembelajaran fisika modernberbasis android menggunakan Adobe Flash CS6 dengan animasi tiga dimensi pada materi model atom untuk siswa kelas XII SMA. Prosiding SNFA (Seminar Nasional Fisika dan Aplikasinya).

Surata, I.K., Sudiana, I.G., \& Sudirgayasa. (2020). Meta-analisis media pembelajaran pada pembelajaran biologi. Journal of Education Technology, 4(1).

Usmeldi. (2017). Efektivitas penerapan media pembelajaran interaktif dengan software autorun untuk meningkatkan kompetensi fisika siswa SMK Negeri 1 Padang. Jurnal Eksakta Pendidikan, 1(1).

Winarno, A., et al. (2009). Teknik evaluasi multimedia pembelajaran panduan lengkap untuk para pendidik dan praktisi pendidikan. Jakarta: Genius Prima Media.

Zaman, Muhammad, Q., et al. (2012). Pengembangan multimedia pembelajaran interaktif menggunakan macromedia flash professional pada mata pelajaran fisika. Indonesian Journal of Curriculum and Educational Technology Studies, 1(1), 67. 